\title{
PRODUÇÃO DE ANTÍGENO SOMÁTICO DE Haemonchus contortus ADULTOS E SEU USOO EM ENSAIO IMUNOENZIMÁTICO INDIRETO PARA DETECÇÃO DE IMUNOGLOBULINA G OVINA
}

\section{Production of somatic extract of adult Haemonchus contortus and its use in an indirect Enzyme-linked Immunosorbent assay for detection of ovine immunoglobulin $G$}

\author{
ROSALINSKI-MORAES, F.,2,3; MINOZZO, J.C. ${ }^{2,4}$; THOMAZ-SOCCOL, V.,
}

\footnotetext{
${ }^{1}$ Programa de Pós-graduação em Processos Biotecnológicos,Setor de Tecnologia, UFPR;

${ }^{2}$ Laboratório de Parasitologia Animal, Departamento de Patologia Básica, UFPR;

${ }^{3}$ PUCPR - Campus Toledo;

${ }^{4}$ Centro de Produção e Pesquisa em Imunobiológico.

Endereço para correspondência: Fernanda Rosalinski-Moraes - fermoraes@uol.com.br
}

\section{RESUMO}

Um dos fatores limitantes à criação de pequenos ruminantes é a verminose gastrintestinal, sobretudo em regiões de clima ameno, onde o Haemonchus contortus é o parasita mais prevalente. Para compreender a resposta imune do ovino a este parasita e identificar os animais mais responsivos, é necessária a adoção de metodologias adequadas para mensurar a resposta imune do hospedeiro. $O$ presente trabalho foi desenvolvido com o objetivo de produzir um antígeno somático de $H$. contortus e utilizá-lo em técnicas de ensaio imunoenzimático indireto (ELISA) para detecção de lgG ovina. Para a obtenção do antígeno, cerca de 1000 helmintos adultos (machos e fêmeas) foram lavados, submetidos à maceração, ciclos de congelamento e descongelamento, sonicação e centrifugação. Foram utilizados como soros controle-positivo 20 amostras oriundas de ovelhas adultas submetidas à infecção natural. Como controle-negativos, foram utilizadas amostras pré-colostrais de 15 cordeiros, bem como de dois borregos mantidos livres de parasitas. Foram testadas várias diluições de antígeno, soros e um conjugado comercial anti-lgG ovina a fim de obter as concentrações ideais. A concentração ótima de antígeno foi de $5 \mu \mathrm{g} \cdot \mathrm{mL}^{-1}$, e as diluições de soro e de conjugado que permitiram melhor discriminação entre positivos e negativos foram, respectivamente, $1: 80$ e $1: 1000$.

Palavras-Chave: IgG, Haemonchus contortus, ELISA.

\section{ABSTRACT}

One of the most limiting factors to the small ruminant husbandry is gastrointestinal verminosis, especially in mild whether regions, where Haemonchus contortus is the predominant worm. To understand sheep immune response to this parasite and to identify the more responsive animals, it is necessary to adopt adequate methods that can measure the host's immune response. This work was conducted in order to produce a somatic extract of $H$.contortus and to employ it in an indirect enzyme-linked Immunosorbent assay (ELISA) to detect ovine IgG. For obtaining the antigen, about 1.000 adult worms (both male and female) were washed, macerated, submitted to freezing and thawing cycles, sonicated and centrifuged. Samples from 20 ewes naturally infected were used as positive standards. Negative standards were 15 pre-colostral samples and those from two lambs 
kept indoors and parasite-free. It was tested several dilutions of antigen, sera and antisheep IgG commercial conjugated in order to obtain the optimal condition. The optimal antigen concentration was $5 \mu \mathrm{g} \cdot \mathrm{mL}^{-1}$ and the optimal dilutions of sera and conjugated were $1: 80$ and $1: 1000$, respectively.

Palavras-chave: IgG, Haemonchus contortus, ELISA.

\section{INTRODUÇÂO}

Um dos principais entraves econômicos à criação de pequenos ruminantes é a verminose (Cabaret et al., 2002; Fao, 2003; Thomaz-Soccol et al., 1996, 2004). Estima-se que mais de 100 milhões de dólares sejam gastos em antihelmínticos no Brasil por ano, o que corresponde a $20 \%$ do mercado de produtos para sanidade animal (Waller, 1994). De uma forma geral, os parasitas coexistem em infecções mistas, sendo que a prevalência de um ou mais gêneros depende do clima da região, da estação do ano, da categoria animal e das condições da propriedade (Nari e Cardozo, 1987; Echevarria, 1996; Moraes et al., 1998; Oliveira et al., 1999). Em regiões de clima ameno e chuvoso, normalmente 0 Haemonchus contortus é o parasito mais importante (O'connor et al., 2006). Portanto, torna-se imprescindível conhecer as formas de interação entre este helminto e seu hospedeiro, de modo a buscar novas alternativas de controle.

A presença de nematódeos gastrintestinais desencadeia uma série de respostas celulares e humorais no hospedeiro, normalmente envolvendo mecanismos Th2- dependentes (Pettit et al. 2005; Pernthaner et al. 2006). Estes mecanismos envolvem 0 aumento do número de eosinófilos circulantes (Schmidt et al. 2001; Rocha et al. 2005) e sua quimiotaxia para a mucosa gastroentérica (Oliveira-Sequeira et al., 2000; Amarante et al. 2005), bem como a produção de anticorpos das classes IgG (Pernthaner et al. 2006), IgA (Amarante et al. 2005; Pernthaner et al. 2006) e lgE (Pettit et al. 2005; Pernthaner et al. 2005).
Estudar o mecanismo de resposta imune em cordeiros frente aos nematódeos gastrintestinais poderia fornecer informações a respeito da imunidade etária, resistência aos helmintos, criar programas de seleção de animais resistentes. Todavia, não existem kits comerciais para estas avaliações. Para proporcionar este tipo de estudo, o presente trabalho foi desenvolvido com o objetivo de produzir um antígeno somático de Haemonchus contortus e padronizar técnicas de ensaio imunoenzimático indireto (ELISA) para detecção de lgG ovina.

\section{MATERIAL E MÉTODOS}

\section{Obtenção do antígeno}

Para a produção do antígeno somático de Haemonchus contrortus (H.c.), helmintos adultos, machos e fêmeas, foram obtidos a partir de ovinos infectados naturalmente e abatidos. Os parasitos foram coletados um a um e lavados sucessivas vezes em solução de cloreto de sódio a $0,9 \%$. Todos os helmintos foram identificados individualmente em microscópio estereoscópico, a fim de se certificar da espécie, seu estádio de desenvolvimento e estado de autólise. Indivíduos imaturos ou com a morfologia alterada por autólise foram descartados.

Os helmintos foram congelados em PBS 7,4 até o preparo do antígeno, que foi obtido segundo Minozzo et al. (2004), com algumas adaptações. Foi procedida a maceração de cerca de 1000 parasitos em uma solução de EDTA a $1 \mathrm{mM}$, em homogeneizador de tecidos (Potter S Biotech Ineternational, 3.01-0699), com ciclos de 150 a $400 \mathrm{rpm}$, até que não se observasse macroscopicamente grandes 
fragmentos. $O$ material resultante foi submetido a cinco ciclos de congelamento em nitrogênio líquido e descongelamento em banho-maria a $37^{\circ} \mathrm{C}$ e a oito séries de 30 segundos no ultra-som $(20 \mathrm{kHz}, 1 \mathrm{~mA})$, com intervalo de 30 segundos.

O próximo procedimento foi a ultracentrifugação a $9000 \mathrm{rpm}$ por 30 minutos. O antígeno solúvel (sobrenadante) foi homogeneizado, aliquotado e estocado a $-18 \stackrel{\circ}{ } \mathrm{C}$. Uma destas alíquotas foi submetida à dosagem de proteína pelo método de Bradford (1976).

\section{Soros-controle}

Para a padronização da técnica de ensaio imunoenzimático e controle da variação entre placas foi necessário a obtenção de controles positivos e negativos para Haemonchus contortus. Os soros controles positivos foram amostras obtidas de ovelhas adultas, de propriedade do Quartel General do Exército da 5무 Região Militar, Curitiba, no final do verão. Os animais eram criados a pasto, sujeitos à infecção natural e apresentavam exames coproparasitológicos positivos para estrongilídeos e com mais de $60 \%$ de larvas de Haemonchus spp. identificadas nas coproculturas.

Como controles negativos, trabalhou-se com 15 amostras de soros pré-colostrais de cordeiros, colhidas no período de 22 de agosto a 7 de setembro de 2000, no Setor de Ovinocultura da Fazenda Experimental do Canguiri, UFPR, Pinhais. As ovelhas foram acompanhadas em baia-maternidade durante o trabalho de parto, sendo realizadas intervenções obstétricas quando necessário. Somente quando a fêmea e o produto apresentavam-se em plenas condições, o cordeiro era separado para a coleta de sangue. O sangue foi colhido da veia jugular externa, após depilação e desinfecção do local de punção. Imediatamente após a coleta, o sangue era passado para tubo de ensaio estéril, onde permanecia até ser levado para o laboratório para centrifugação e obtenção do soro.

$O$ segundo controle negativo foi obtido de dois cordeiros, tratados com antihelmínticos e mantidos confinados desde o desmame. Estes animais também eram pertencentes ao Setor de Ovinocultura da Estação Experimental do Canguiri. Dois meses após o confinamento, cada um recebeu uma dose de Levamisol (10 mg.kg ${ }^{-1}$; Ripercol $150 \mathrm{~F} \AA$ - Cyanamid Química do Brasil). Quinze dias após esta dosificação, os animais receberam uma dose de Nitroxinil (13 mg. $\mathrm{kg}^{-1}$; Dovenix ${ }^{\circledR} 34 \%$ - Laboratórios Merial - Uruguai). Três meses após a primeira dosificação, foram colhidas as amostras de soro.

\section{Padronização da Técnica de Ensaio} Imunoenzimático para detecção de IgG ovina anti- H.c.

$\mathrm{O}$ protocolo a ser padronizado foi adaptado de MINOZZO et al.(2004). O antígeno H.c. foi diluído em tampão carbonato-bicarbonato, $\mathrm{pH} 9,6$, até as concentrações de $5 ; 2,5$ e $1,25 \mu \mathrm{g} \cdot \mathrm{mL}^{-1}$, que foram testadas na padronização. Este tampão foi escolhido por apresentar melhores condições para adesão do antígeno H.c. à placa (SCHALLIG et al., 1995). Foram adicionados $100 \mu \mathrm{L}$ de solução antigênica por poço e a placa foi incubada overnight a 4-8 $\stackrel{\circ}{\mathrm{C}}$. O excesso de antígeno foi removido por duas lavagens. 0 bloqueio dos poços foi realizado com 150 $\mu \mathrm{L}$ de uma solução de $2 \%$ de caseína bovina, por uma hora, a $37^{\circ} \mathrm{C}$. Para avaliar o nível de reações inespecíficas devido a anticorpos presentes no soro, alguns poços sem antígeno foram bloqueados. $O$ excesso de caseína foi removido por duas lavagens.

Um volume de $100 \mu \mathrm{L}$ de várias diluições de soro teste foi analisado em duplicata. Além dos soros-teste, uma amostra de soro controle positivo e uma de controle negativo foram adicionadas a cada placa, a fim de controlar possíveis variações entre placas. Para padronizar a 
diluição ideal de soro, foram testadas as diluições de 1:40 e 1:80. Os soros foram incubados a 37 ㅇ $\mathrm{C}$ por uma hora, e procedidas seis lavagens.

O conjugado utilizado consistia em anticorpos contra $\operatorname{lgG}$ ovina e marcados com a enzima peroxidase (SIGMA A3415). Após vários testes iniciais, optou-se por testar as diluições de 1:1000 e 1:2500, em um volume total de $100 \mu \mathrm{L}$ por poço. Então, a placa foi incubada a $37 \stackrel{\circ}{\circ} \mathrm{C}$ por uma hora e novas seis lavagens procedidas.

O OPD (orto-fenileno-diamina, SIGMA P6787) foi utilizado como substrato e o peróxido de hidrogênio, como catalizador, tendo o tampão citrato, pH 5,0 como veículo. Após adição de $100 \mu \mathrm{L}$ desta mistura por poço, a placa foi incubada em temperatura ambiente, por 15 minutos, ao abrigo de luz. A reação foi interrompida pela adição de $50 \mu \mathrm{L}$ por poço de uma solução de ácido sulfúrico a $5 \%$. Os valores de absorbância foram obtidos em leitora (BioRad-Model 550) com filtro de $492 \mathrm{~nm}$.

\section{Determinação de reações inespecíficas}

O grau de reações inespecíficas ocasionado pelas diferentes diluições de soro também foi analisado nas placas de padronização. Para isto, a técnica foi realizada conforme descrito acima, porém sem sensibilização do antígeno H.c.

\section{Ponto de corte}

O ponto de corte da reação entre soros reagentes e não reagentes, foi determinado pela média aritmética dos valores de absorbância das amostras de soros controle negativo acrescido de dois desvios padrão da média.

\section{RESULTADOS}

Quantidade de antígeno para sensibilização da placa no ensaio para detecção de $\lg G$ anti- H.c.

A concentração protéica do antígeno H.c. foi estimada em $5 \mathrm{mg} \cdot \mathrm{mL}^{-1}$ pelo método de Bradford (1976). Quando as concentrações de 5; 2,5 e 1,25 $\mu \mathrm{g}$ de antígeno por $\mathrm{mL}$ foram testadas com os soros controles diluídos 1:80 e o conjugado 1:1000, pôde-se observar melhor distinção entre os soros positivos e negativos na concentração de $5 \mu \mathrm{g}$ de antígeno por $\mathrm{mL}$ (figura 1). Como as placas foram sensibilizadas com $100 \mu \mathrm{L}$ da solução antigênica por poço, esta concentração (5 $\mu \mathrm{g} \cdot \mathrm{mL}^{-1}$ ) corresponde à quantidade de 500 ng de antígeno por poço.

Quando as amostras de soro diluídas 1:40 foram incubadas em poços sem antígeno, valores muito altos de absorbância foram obtidos, sobretudo para os controles positivos (média de 0,088 $\pm 0,014$ de absorbância). Ao aumentar a diluição para $1: 80$, os valores de absorbância para reações inespecíficas caíram para níveis menores (média de 0,014 $\pm 0,019$ de absorbância).

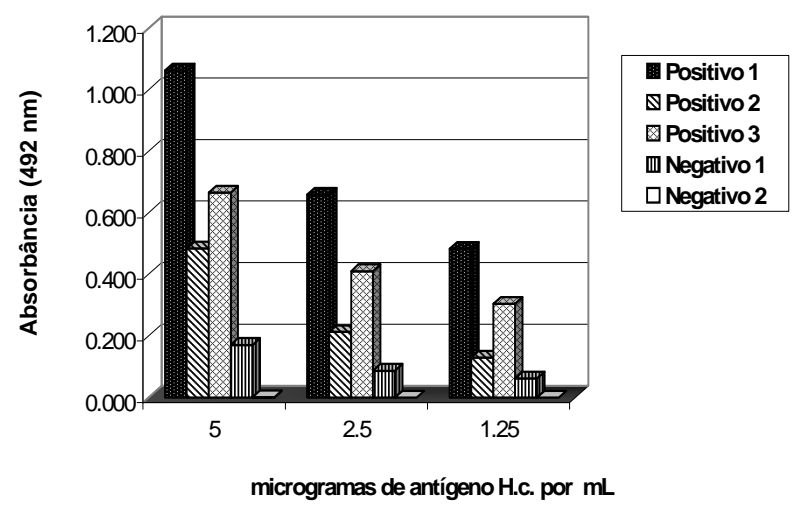

Figura 1 - Valores de absorbância dos soros de ovinos positivos e negativos para Haemonchus contortus em função da concentração de antígeno somático do parasito adulto, quando os soros foram diluídos 1:80 e o conjugado anti-igg ovina 1:1000. NOTA: Soros controles positivos 1, 2 e 3 obtidos de ovelhas adultas durante o final do verão; soro controle negativo 1 proveniente de cordeiro tratado e mantido em condições livres de parasitismo por dois meses; soro controle negativo 2 corresponde a uma amostra de soro pré-colostral. 


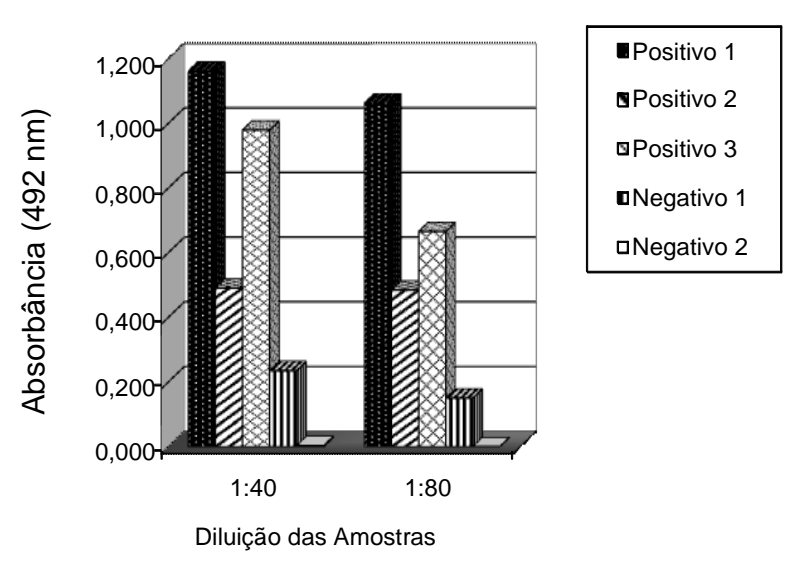

Figura 2 - valores de absorbância dos soros de ovinos positivos e negativos para Haemonchus contortus (H.c.) em função da diluição dos soros controles, quando a placa foi sensibilizada com solução antígeno a $5 \mu \mathrm{g} . \mathrm{ml}-1$ e o conjugado anti-igg ovina foi diluído 1:1000. NOTA: Soros controles positivos 1, 2 e 3 obtidos de ovelhas adultas durante o final do verão; soro controle negativo 1 proveniente de cordeiro tratado e mantido em condições livres de parasitismo por dois meses; soro controle negativo 2 corresponde a uma amostra de soro pré-colostral.

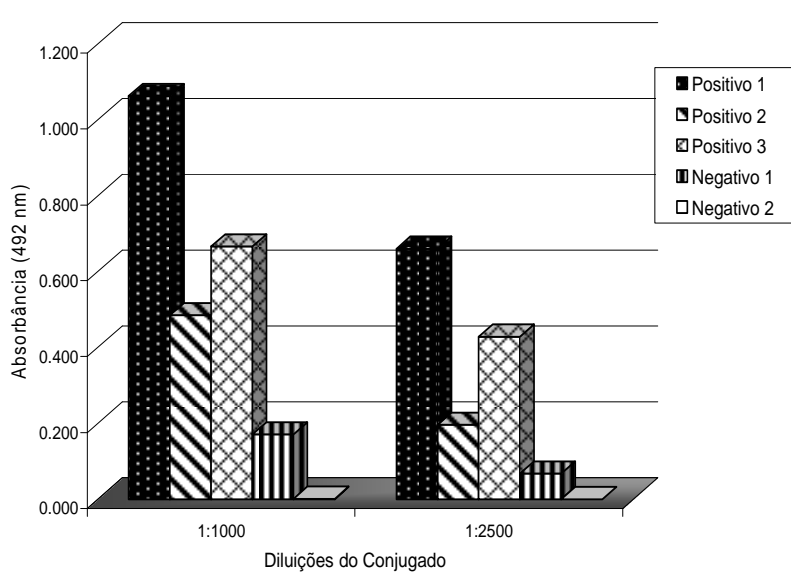

Figura 3 - Valores de absorbância dos soros de ovinos positivos e negativos para Haemonchus contortus em função da diluição do conjugado antiigg ovina, quando a placa foi sensibilizada com 5 $\mu \mathrm{g} . \mathrm{ml}-1$ de antígeno e os soros controles foram diluídos a 1:80. NOTA: Soros controles positivos 1, 2 e 3 obtidos de ovelhas adultas durante o final do verão; soro controle negativo 1 proveniente de cordeiro tratado e mantido em condições livres de parasitismo por dois meses; soro controle negativo 2 corresponde a uma amostra de soro pré-colostral.
Padronização da diluição do conjugado

Ao manter fixa a quantidade de antígeno em $5 \mu \mathrm{g} \cdot \mathrm{mL}^{-1}$ e a diluição do soro em 1:80, pôde-se observar importante redução nos valores de absorbância na diluição de 1:2500, quando comparada à 1:1000. (figura 3). Por isso, a diluição de $1: 1000$ foi escolhida para a continuidade do trabalho.

\section{Ponto de corte \\ Mantendo-se fixa a concentração} protéica do antígeno em $5 \mu \mathrm{g} \cdot \mathrm{mL}^{-1}$, a diluição do soro em 1:80 e a diluição do conjugado em 1:1000, a média de valores de absorbância para os soros controlesnegativos foi de 0,213 e o desvio padrão de 0,033 . Portanto, o valor mínimo de absorbância para que a amostra possa ser considerada reagente ao teste foi de 0,279.

\section{DISCUSSÃO}

A concentração de $5 \mu \mathrm{g}$ de antígeno somático de Haemonchus contortus adultos por $\mathrm{mL}$ de tampão carbonato, para avaliação de resposta imune-humoral também foi utilizada por Schallig et al. (1995), Gómez-Muñhoz et al. (1998) e Amarante et al. (2005). Cuquerella et al. (1994) utilizaram a concentração de 5 $\mu \mathrm{g} \mathrm{mL}{ }^{-1}$ de antígeno somático de $\mathrm{L}_{3}$ de H.c.. Porém, quando o antígeno foi obtido a partir de parasitos adultos, a concentração empregada foi a de $10 \mu \mathrm{g} \mathrm{mL}^{-1}$. Portanto, a concentração de antígeno utilizada neste trabalho está coerente com a utilizada por outros autores e permite estudos de avaliação da resposta imune humoral em ovinos.

A diluição do soro em 1:80 proporcionou melhor distinção entre os controles positivos e negativos, bem como a diminuição da ocorrência de respostas inespecíficas. Este é o fator que mais varia na padronização de testes de imunoenzimáticos. Para detecção de IgG anti-H.c., foram encontradas diluições de 1:100 (Cuquerella et al., 1994) a 1:1000 
(Gómez-Muñhoz et al.,1998). A diluição ótima dos soros depende de outras condições padronizadas no teste, como a concentração de outros reativos empregados e do tempo de incubação em cada fase do enzima-imunoensaio. Estas variáveis mudam conforme a rotina de cada laboratório, tornando difícil a utilização de uma mesma diluição de soro para todos os ensaios. Outro fator que pode influenciar na diluição de soro escolhida é a concentração de anticorpos presentes na população teste. Desta forma, um conjunto de amostras que apresente altos títulos de anticorpos específicos tende a ser analisadas sob maior fator de diluição. Neste trabalho, as amostras teste eram todas provenientes de ovinos com infecção de helmintos gastrintestinais natural. É possível que estes animais tenham apresentado menores títulos de anticorpos que animais submetidos a infecções experimentais com alto nível de desafio. Isto explicaria o menor fator de diluição de soros empregado neste trabalho se comparado com o de outros autores. Todavia, ele está mais próximo da realidade a ser encontrada a campo.

Como o conjugado é o reativo de maior custo em uma prova de imunoensaio, tenta-se utilizar a maior diluição possível do mesmo, desde que isto não diminua significativamente os valores de absorbância dos soros ao ponto de prejudicar a distinção entre controles positivos e negativos. Neste estudo foi utilizado um conjugado comercial, cuja recomendação do fabricante é a titulação do mesmo por meio de diluições sucessivas até 1:10000. A diluição de $1: 1000$ foi a que mostrou valores mais satisfatórios de absorbância para os soros controles.

Embora a diluição ótima de conjugado dependa de suas características intrínsecas e das condições do ensaio, é comum o uso de conjugados comerciais na diluição de 1:1000 (Cuquerella et al., 1994;
Schallig et al., 1995; Gómez-Muñoz et al., 1998; Amarante et al., 2005).

A resposta imune do hospedeiro pode limitar o estabelecimento da carga parasitária. Além disso, ela está sob controle genético, com valores de herdabilidade entre 0,30 e 0,50 (Douch et al.,1996; Amarante et al., 2004). Isto possibilitou a criação de programas de seleção de ovinos resistentes às parasitoses, inclusive com a possibilidade de utilizar o nível de IgG anti-helminto como marcador em outros países (Douch et al.,1996; Bisset et al.,2001). No entanto, existem algumas evidências de que a reação de hipersensibilidade possa trazer prejuízos ao hospedeiro. Linhagens resistentes de ovinos tendem a apresentar maiores escores de diarréia quando submetidos a infecções por Trichostrongylus spp. e Ostertagia spp. (Bisset et al.,1992).

A técnica de detecção de IgG antiH.c. aqui padronizada pode ser uma ferramenta útil para estudar a resistência e a tolerância dos ovinos aos helmintos gastrintestinais, bem como de selecionar animais que sejam resistentes ou susceptíveis à parasitose. Esta metodologia será validada em ovelhas adultas e cordeiros de rebanhos paranaenses para verificar sua eficácia como marcador de animais resistentes, isoladamente ou em conjunto com outras variáveis.

\section{CONCLUSÃO}

É possível a produção de antígeno a partir de indivíduos adultos da espécie Haemonchus contortus e o seu uso em métodos de ensaio imunoenzimático para detecção de anticorpos ovinos da classe $\operatorname{lgG}$. A concentração ótima de antígeno por poço foi de 500 ng e as diluições ótimas de soro e conjugado foram, respectivamente, $1: 80$ e $1: 1000$. 


\section{REFERÊNCIAS}

AMARANTE, A.F.T; BRICARELLO, P.A.; HUNTLEY, J.F.; MAZZOLIN, L.P.; GOMES, J.C.; Relationship of abomasal histology and parasitespecific immunoglobulin $A$ with the resistance to Haemonchus contortus in three breeds of sheep. Veterinary Parasitology, v.128, p.99-107, 2005.

AMARANTE, A.F.T; BRICARELLO, P.A.; ROCHA, R.A.; GENNARI, S.M. Resistance of Santa Inês, Suffolk and lle de France lambs to naturally acquired gastrointestinal nematode infections. Veterinary Parasitology, v. 120, p.91-106, 2004.

BISSET, S.A.; VLASSOFF, A.; MORRIS, C.A.; SOUTHEY, B.R.; BAKER, R.L.; PARKER, A.G.H. Heritability of and genetic correlations among faecal egg counts and productivity traits in Rommey sheep. New Zealand Journal of Agricultural Research, n.35, p. 51-58, 1992.

BISSET, S.A.; MORRIS, C.A.; McEWAN; VLASSOFF, A. Breeding sheep in New Zealand that are less reliant on anthelmintics to maintain health and productivity. New Zealand Veterinary Journal, v.49, n.6, p.236-246. 2001.

BRADFORD, M.M. A rapid and sensitive method for the quantitation of microgram quantities of protein utilizing the principle of protein dye-binding. Analytical Biochemistry, v. 42, p. 248-254, 1976.

CABARET, J.; MAGE, C.; BOUILHOL, M. Helminth intensity and diversity in organic meat sheep farms in centre of France. Veterinary Parasitology, $v$. 105, n.1, p.33-47. 2002.

CUQUERELLA, M.; GÓMEZ-MUÑHOZ, M.T.; CARRERA, L.; FUENTE, C.; ALUNDA, J.M. Cross antigenicity among ovine trichotrongyloidea. Preliminary report. Veterinary Parasitology, v.53, p.243-251, 1994.

DOUCH, P.G.C.; GREEN, R.S.; MORRIS, C.A.; McEWANS, J.C.; WINDON, R.G. Phenotypic markers for selection of nematode-resistant sheep. International Journal for Parasitology, v. 26, n.8/9, p. 899-911, 1996.

ECHEVARRIA, F. Epidemiologia de nematódeos e controle estratégico em ovinos lanados. In: PADILHA, T. Controle dos Nematódeos Gastrintestinais em Ruminantes. Coronel Pacheco: EMBRAPA, 1996. p. 157-168.

FAO, Salud Animal. Resistência a los Antiparasitarios: Estado Actual Énfasis en América Latina. Roma: FAO, 2003. 52p.
GOMEZ-MUÑOZ, M.T.; CUQUERELLA, M.; FUENTE, C.; GÓMEZ-IGLESIAS, L.A.; ALUNDA, J.M. Infection-induced protection against Haemonchus contortus in Merino and Manchego sheep - ralationship to serum antibody response. Journal of Veterinary Medicine - Series B, v.45, p. 449-459, 1998.

MINOZZO, J.C.; THOMAZ-SOCCOL, V.; OLORTEGI, C.C; SOARES, V.E.; COSTA, A.J. Enzyme-linked immunosorbent assay (ELISA) for imunodiagnostic of bovine cysticercosis and kinetics of antibodies production against-Cysticercus bovis. Ciencia Rural. v. 34, n. 3, 2004.

MORAES, F.R.; SARNOSKI Jr; S.; SAULT, J.P.E.; OLIVEIRA; V.P.; SOCCOL, V.T.; CASTRO, E.A. Estudo epidemiológico da verminose ovina na Região de Ponta Grossa - PR. In: EVINCI - Evento de Iniciação Científica da Universidade Federal do Paraná, 6.,1998, Curitiba. Anais... Curitiba: Editora da Universidade Federal do Paraná, 1998. p. 427.

NARI, A.; CARDOZO, H. Nematodos Gastrointestinales. In.: Enfermidades de los lanares - Tomo I. Montevideo : Editorial Agropecuaria Hemisferio Sur S.R.L., 1987. p.1-51.

O'CONNOR, L.J.; WALKDEN-BROWN, S.W.; $\mathrm{KAHN}$, L.P. Ecology of the free-living stages of major trichostrongylid parasites of sheep. Veterinary Parasitology, v.142, n.1-2, p.1-15. 2006.

OLIVEIRA; V.P.; MORAES, F.R.; ZAGO, M.; POLLATI, L.; SOUZA, F.P.; THOMAZ-SOCCOL, V.; CASTRO, E.A. Epidemiologia da verminose em ovinos na Região de Guarapuava - Paraná. In: EVINCI - Evento de Iniciação Científica da Universidade Federal do Paraná, 7.,1999, Curitiba. Anais... Curitiba: Editora da Universidade Federal do Paraná, 1999. v.2. p. 494.

OLIVEIRA-SEQUEIRA, T.C.G.; AMARANTE, A.F.T.; SEQUEIRA, J.L. Parasitological characteristics and tissue response in the abomasum of sheep infected with Haemonchus spp. Arquivo Brasileiro de Medicina Veterinária e Zootecnia, v. 52, n.5, p.447-452, 2000.

PERNTHANER, A.; SHAW, R.J.; MCNEILL, M.M.; MORRISON, L.; HEIN, W.R. Total and nematodespecific IgE response in intestinal lymph of genetically resistant and susceptible sheep during infection with Trichostrongylus colubriformis. Veterinary Immunology and Immunopathology, v. 104 , p. $69-80.2005$. 
PERNTHANER, A.; COLE, S.A.; MORRISON, L.; GREEN, R.; SHAW, R.J.; HEIN, W.R. Cytokine and antibody subclass responses in the intestinal lymph of sheep during repeated experimental infections with nematode parasite Trichostrongylus colubriformis. Veterinary Immunology and Immunopathology, v.114, p. 135-148. 2006.

PETTIT, J.J.; JACKSON, F.; ROCCHI, M.; HUNTLEY, J.F. The relationship between responsiveness against gastrointestinal nematodes in lambs and the numbers of circulating IgE-bearing cells. Veterinary Parasitology, v. 134, p.131-139. 2005.

ROCHA, R.A.; AMARANTE, A.F.T.; BRICARELLO, P.A. Resistance of Santa Ines and lle de France suckling lambs to gastrointestinal nematode infections. Revista Brasileira de Parasitologia Veterinária, v.14, n.1; p. 17-20, 2005.

SCHALLIG, H.D.F.H.; HORNOK, S.; CORNELISSEN, J.B.W.J. Comparison of two enzyme immunoassays for the detection of Haemonchus contortus infections in sheep. Veterinary Parasitology, v.57, p. 329-338, 1995

SCHMIDT, E.M.S.; LOCATELLI-DITTRICH, R.; THOMAZ-SOCCOL, V.; MORAES, F.R. Pesquisa de marcadores parasitológicos e hematológicos de resistência ao parasitismo gastrintestinal em cordeiros. Arquivos de Ciências Veterinárias e Zoologia UNIPAR ,v. 4, n. 1, p. 55-64, 2001.

THOMAZ-SOCCOL, V.; SOTOMAIOR, C.; SOUZA, F.P.; CASTRO, E.A.; PESSÔA SILVA, M.C.; MILCZEWSKI, V. Occurence of resistance to antihelmintics in sheep in Paraná State, Brazil. The Veterinary Record. v. 139, p. 421-422, 1996.

THOMAZ-SOCCOL, V.; SOUZA, F.P.; SOTOMAIOR, C.; CASTRO, E.A.; MILCZEWSKI, V.; PESSOA, M. C.; MOCELIN, G. Resistance of gastrointestinal nematodes of anthelmintics in sheep (Ovies aries). Brazilian Archives of Biology and Technology. v. 47, p. $41-47,2004$.

WALLER, P.J. The development of anthelmintic resistance in ruminant livestock. Acta Tropica, v. 56, p. 233-243, 1994. 